\title{
Engaging with Political and Social Issues on Facebook in College Life
}

\author{
Yiran Wang \\ Department of Informatics \\ University of California, Irvine \\ yiranw2@uci.edu
}

\author{
Gloria Mark \\ Department of Informatics \\ University of California, Irvine \\ gmark@uci.edu
}

\begin{abstract}
College students are exposed to a vast amount of information on political and social issues through social media. We studied how college students engage with political and social issues on Facebook in a weeklong study with 50 participants using diary entries and interviews. The interviews revealed a duality of benefits for using Facebook for news and they also revealed challenges of selfpresentation around news. Benefits included gaining multiple perspectives and enabling social sense making, providing personal relevance and convenience of access, and the opportunity for social engagement. Impression management and disclosure concerns strongly influence some people to refrain from commenting or sharing news. We discuss the challenges that context collapse poses for Facebook news readers. We suggest design ideas and future directions to encourage more balanced participation with news among college students.
\end{abstract}

\section{Author Keywords}

Facebook; political engagement; social media; news consumption; impression management; context collapse

\section{ACM Classification Keywords}

H.5.3 Information Interfaces and Presentation (e.g., HCI): Group and Organization Interfaces; K.4.3 Computers and Society: Organizational Impacts.

\section{INTRODUCTION}

In the past decade, social media sites like Facebook have evolved from an online social place for friend interaction to a gateway to the outside world. The rise of social media has affected many aspects of modern life. More and more people are utilizing a variety of social media sites for their news needs [5, 6]. For example, a 2015 Pew Research report [5] found that $63 \%$ of Facebook users overall, and $74 \%$ of young adults (ages 18-34) on Facebook, use the platform as a source of news about events and issues

\footnotetext{
Permission to make digital or hard copies of all or part of this work for personal or classroom use is granted without fee provided that copies are not made or distributed for profit or commercial advantage and that copies bear this notice and the full citation on the first page. Copyrights for components of this work owned by others than ACM must be honored. Abstracting with credit is permitted. To copy otherwise, or republish, to post on servers or to redistribute to lists, requires prior specific permission and/or a fee. Request permissions from Permissions@acm.org. CSCW '17, February 25-March 01, 2017, Portland, OR, USA

(C) 2017 ACM. ISBN 978-1-4503-4335-0/17/03...\$15.00

DOI: http://dx.doi.org/10.1145/2998181.2998295
}

beyond friends and family. Different from traditional cable news or online news sites, these users can further disseminate information and voice perspectives, promoting and curating information directly for their social connections.

Given this changing media landscape, how do college students engage with news on social media? This is an important question to address because young adults (ages 18-25) are in a life stage of "emerging adulthood," a critical period of time for exploring worldviews [3] and political identities [37]. College experience introduces diverse perspectives to young adults who are often open and willing to change their worldviews [32]. The wide adoption of social media could lead college students to be more open to exploration and change because 1) politics and social issues can be frequently found on social media, presented in more informal and personalized formats such as personal stories, photo journals, infographics, online memes, and video commentaries; and 2) studies have suggested that youth responded to and engaged better with politics when the materials were presented in informal formats such as a comedy sketch [8]. Therefore, college students are exposed to political and social issues in a way that might have a particular impact on them.

While some researchers praise new media tools for facilitating participatory politics [21, 34], others are concerned that young people's political knowledge or offline civic actions (e.g., voting) have not increased [7, 9]. In addition, a recent study [31] takes a more nuanced approach to the role of social media in online news consumption, by identifying the benefits (e.g., facilitating social sense-making) as well as the drawbacks (e.g., lack of objectivity, depth, or focus). We seek to understand both the gratifications and caveats of interacting with news on social media for college students who are in a life stage where they are actively figuring out their stances on critical social and political issues.

We also extend the work on disclosure and impression management by examining college students' political engagement on social media. We think this is an important line of inquiry because a person's viewpoints on politics and social issues reflect their value and moral judgment, a critical aspect of a person's identity. Exploring how they negotiate such identity in online social networks helps further our understanding of their news behavior. 
Scholarship on online impression management has addressed self-disclosure strategies [44], data curation practices [36, 48], and self-image presentation [14, 23]. These studies have focused on tactics for managing relatively unserious content, such as hiding embarrassing lyrics or unflattering photos from one's personal data history [36]. We set out to explicitly look at how one engages in political information from the lens of impression management as well as political disclosure since few studies have examined this [27, 38]. An in-depth understanding of people's goals, concerns, and practices from such a perspective has important implications for the design of social media sites. Specifically, the affordances of a site, such as anonymity, ephemerality, and persistence, influence how a user makes decisions about disclosing their viewpoints and managing their image around often debatable if not sensitive topics. These decisions further impact how and to what extent politics and social issues are disseminated and discussed in a public space.

Even though young people use a range of social media sites (e.g., Reddit, Twitter) to access news on political and social issues $[5,6]$, we focus on Facebook for the scope of this paper because Facebook is the most heavily used social media site for college students [46]. We chose Facebook also because people have their real life identity linked to the site, increasing the need for managing their selfpresentation. The overall research question that guides our investigation is: how do Facebook users in college engage with news concerning political and social issues? Because of the exploratory nature of the question, we conducted a qualitative investigation through diaries and interviews.

\section{RELATED WORK}

\section{News and Politics in Social Media}

Online news consumption and participation can contribute to network heterogeneity, the diversity of people with whom a person interacts [35]. In the context of political discussion, network heterogeneity is measured by the user's frequency of discussing politics with people of different gender, race, political ideology, or partisan affiliation [11, 35]. News consumption and news sharing on social media were both found to contribute to network heterogeneity, while the effect can be different depending on the individual's level of political interest [12]. A number of recent empirical studies showed a positive relationship between social media and political outcomes. Specifically, social media use can facilitate serendipitous exposure to political differences [38] and promote both online and offline political participation [17]. Comparing different types of news participation, Oeldorf-Hirsch and Sundar [29] found that asking opinions in one's network, tagging specific friends, and commenting on news all led to greater involvement in the news content.

A competing line of studies claimed that despite the increasing popularity of social media for young people in accessing news, their political knowledge or civic participation has not improved compared to those who used traditional means for reading news [7, 24]. For example, while college students geared their attention more towards Internet sources to become informed for the 2008 U.S. election, attention to social media alone for campaign information was not significantly associated with political self-efficacy and political involvement [24]. In addition, Grevet et al. [18] observed that political contention on Facebook is more likely to cause friction in friendship than to encourage conversations between different sides, resulting in more polarized views among politically engaged users. Similarly, other studies $[20,28]$ have also found that people have the tendency to connect with likeminded peers and pay attention to information that aligns with their values. The selective exposure and echo chamber effects prevent diverse viewpoints $[16,25,40]$.

As a result, researchers have used various design interventions to help people engage in more diverse views in social media, such as indicating the expertise level of the commenters [25], showing anonymized social annotations based on dimensions of similarity [2], aggregating multiple social media sources [38], and allowing flexible management of one's identity (e.g., anonymous vs. identifiable) [38].

Taken together, there are inconsistent findings regarding the effects of social media in promoting people's political interest and engagement. While most studies have investigated this topic using self-reports in surveys or in experimental settings $[11,12,17,25,29]$, we believe it is important to conduct a qualitative investigation, focusing on college students' practices in-situ. With a contextual understanding of how college students read, understand, and respond to news, we seek to extend the line of research on introducing design interventions to diversify political engagement on social media.

\section{Disclosure, Context Collapse, and Impression Management in Social Media}

Plenty of research has investigated how people manage their self-presentation with online media $[14,23,36,44$, 48]. The appropriateness and relevance of the content to the context is a key factor that motivates users' curating decisions. On Facebook, people manage their presentations of self by curating emotional content, irrelevant content to the current context, their overall image, and friend list [48]. In addition to Zhao et al.'s work [48], Schoenebeck et al. [36] has also highlighted the importance of temporality in studying impression management by showing how young adults went to great lengths to retrospectively manage their past appearances. Since young adults' worldviews and political identities are likely to evolve in college, understanding how college students present themselves around news in light of these potential changes is important.

Disclosure and self-presentation are intertwined. People adopt various self-disclosure strategies essential for managing self-presentation goals such as social approval, 
identity clarification, and social control [44]. Vitak and Kim [44] observed four types of such strategies: granting or limiting friend access, disclosing to a targeted audience, self-censorship, and disguising content (by using other communication channels or giving code names for the content). A great challenge that can render these disclosure strategies ineffective or costly is the concept of context collapse - "the flattening out of multiple distinct audiences in one's social network" [43]. Because each audience group can value different sets of appropriate behaviors and social norms, tensions arise when individuals interact with multiple audiences in one single platform [43]. Different audience groups in previous studies were often implicitly categorized according to the offline social structure, such as family, co-workers, and classmates [44, 45]. We think that content such as politics can also lead to distinct audience groups due to conflicting beliefs and values, thus creating disclosure and self-presentation challenges for the users.

Most studies on impression management focused on relatively unserious content, such as choosing profile images [23], managing inappropriate tagged photos or comments from friends [44], or curating casual and personal content on one's own data archive (i.e., timelines) [48]. However, very few studies explicitly examined impression management and disclosure associated with relatively more serious topics such as politics [27, 38]. As Facebook use has gradually shifted away from the documentation of daily whereabouts [36] to increasing news consumption and participation, we believe that it is important to create an account of how Facebook users negotiate the presentation of self around topics of politics and social issues.

\section{METHODS}

\section{Participants and Procedure}

Fifty undergraduate students from a large public university on the U.S. West Coast participated in a weeklong study from January to April 2016. We recruited the participants by posting announcements on the official university Facebook groups for the classes of 2016-2019. We chose the official university Facebook groups because there were

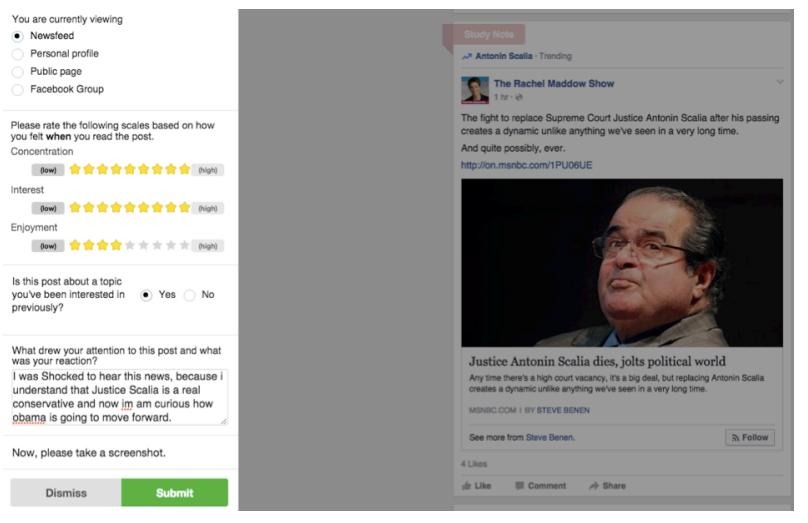

Figure 1. Example of a diary entry a large number of current students affiliated with these groups. We also made announcements and collected signups from large undergraduate classes. After the initial recruitment, we sent out a screening survey asking how often they used Facebook on a typical day and what was their primary platform for Facebook use (i.e., desktop or mobile). This is part of a larger study where we investigate how college students use Facebook for interest-based and self-directed informal learning. Because of the focus on Facebook, we only invited students who self-reported using Facebook for at least three times a day to participate in the study.

In the beginning of the study, we installed a web browser plug-in ROSE [33] on participants' laptops. ROSE allowed participants to take diary notes in the Facebook interface. We asked the participants to use Facebook as they would normally and make a diary note using ROSE if they encountered any content on Facebook that they considered interesting, meaningful, or of value to them, from which they felt they could learn something. We also instructed them to take a screenshot of the content of the post, as ROSE did not record content from Facebook. We refer to the diary note and screenshot as a diary entry. Figure 1 is an example of a diary entry we collected. In order for us to minimize the disruption and for the participants to maintain as normal a Facebook use experience as possible, we instructed the participants that they did not need to make diary entries for repeating topics. For instance, if a participant was interested in the 2016 presidential election and encountered a large number of posts on this topic, we asked them to only make diary entries on selective posts that had more significance for them. Therefore, the number of diary notes is a selected representation by the participants of information they found interesting and of learning value in the period of a week. At the end of the seven-day study, we conducted semi-structured interviews using the diary notes as prompts. The first author conducted all 50 interviews. The interview lengths ranged from 25 to 96 minutes, with an average of 45 minutes. Interviews were fully transcribed for analysis. Participants also filled out a general survey at the end of the study, where they reported demographic information. Participants were compensated $\$ 50$ upon the completion of the study.

We started each interview by asking general questions such as what were the participants' primary reasons for using Facebook; what type of content they generally found interesting, meaningful, or of personal value on Facebook; and how they use Facebook currently compared to how they used it when they first started. In responding to these questions, if the participants mentioned information about news of current events, politics, or social issues, we encouraged them to further discuss where they got this type of content on Facebook and outside of Facebook, why they paid attention to such content, how they evaluated its quality, whether they interacted with such content, and why (not). Afterwards, we asked each participant to choose two 
or three diary entries that they found the most interesting or important to discuss extensively. If their diaries covered multiple topics (e.g., science, technology, and politics), we encouraged the participant to pick the most interesting one or two examples for each topic. For each diary note, we asked the participants to discuss the content of the information, why they felt it was of learning value to them, how they encountered the information, and what they did after reading the information and why. If the participant did not mention any topics relevant to news, politics, or social issues, we asked them at the end of the interview whether they read information on those topics, and if not, what were the reasons.

The sample of 50 participants $(M=21, F=29)$ were of relatively balanced class standing (freshman $=11$, sophomore $=12$, junior $=13$, senior $=14$ ). Their ages ranged from $18-25$, with a median of 20 . A total of 373 diary notes were received, which covered various topics from science, technology, politics and social issues, life hacks, and career development. For the scope of this paper, we only focus on the general comments and diary entries that concerned politics and social issues, operationalized below.

\section{News, Politics, and Social Issues}

The first author and one research assistant discussed which general comments and diary notes were related to political and social issues. By political, we refer to topics relating to the government and public affairs of a country. By social issues, we used a criterion of the most popular social issues of 2016 [41] and also included stigmatized topics such as mental illness as they are of increasing societal concern.

In the general comments in the interviews, participants mainly discussed topics of the 2016 U.S. presidential election, national and international affairs, LGBT rights, and climate change. We collected 103 diary notes on the topics of politics and social issues, with a median number of two per participant. To remind the reader, these were topics that the participants selected as most representative of their interests. In the interviews, 51 of these diary notes were selected by 38 participants to be extensively discussed. The remaining 12 participants did not make any diary notes related to politics or social issues. Topics included the current election, political topics other than the election, issues of gender, race, and related public policy debates, national and international affairs, stigmatized topics (e.g., mental breakdown, anxiety disorders), and the U.S. economy. Table 1 summarizes the detailed information of these topics. Though some of the political or social issues discussed were in the format of personal reflections, photo journals, or video commentaries - that is, not in the form of a news article, they are nevertheless directly connected to current news events or social issues. Therefore, in the rest of the paper, we use the term "news" and "social and political issues" interchangeably.

\section{Coding and Themes}

We used an inductive approach to analyze the interview data $[13,26]$. From the initial round of coding, 94 open codes were produced, which were grouped into four early themes surrounding news sources, value of engaging with news on Facebook, tactics of interacting with Facebook news, and how one perceives or presents themselves in relation to news on Facebook. The first author used axial coding to identify categories in each theme. Through constant comparison and memoing, two main themes emerged from the data. Both authors then discussed and refined these themes.

With regards to the news source, we identified four major student profiles from the data: students who primarily get news from Facebook, students who primarily get news from mainstream media news outlets (e.g., The New York Times, $\mathrm{CNN}$ ), students who primarily get news from other online sources (e.g., Reddit), and students who do not usually read news or are interested in news. Within the category of primarily Facebook news readers, we identified four subcategories of students based on the specific source they primarily rely on in Facebook: friends, trending topics, subscribing to mainstream news outlets (e.g., BBC, the Atlantic, the official page of Bernie Sanders), and subscribing to popular media producers (e.g., Buzzfeed News, NowThis, AJ+). Then, a second coder, who had not participated in creating the codes, independently coded the 50 participants based on 1) the four major profiles and 2) if the participant was primarily a Facebook news reader, the

\begin{tabular}{|c|c|c|}
\hline Topics & Examples & $\begin{array}{c}\text { \# of } \\
\text { diaries }\end{array}$ \\
\hline $\begin{array}{c}\text { 2016 U.S. } \\
\text { election }\end{array}$ & $\begin{array}{c}\text { Bernie Sanders campaign; } \\
\text { Trump attacks Clinton; Super } \\
\text { delegates }\end{array}$ & 18 \\
\hline $\begin{array}{c}\text { Other } \\
\text { political } \\
\text { topics }\end{array}$ & $\begin{array}{c}\text { First female Native American } \\
\text { federal judge; Bill Clinton } \\
\text { addresses Black Lives Matter } \\
\text { protesters }\end{array}$ & 8 \\
\hline $\begin{array}{c}\text { Gender, } \\
\text { race, and } \\
\text { public } \\
\text { policies }\end{array}$ & $\begin{array}{c}\text { Stereotype Asians; Objectify } \\
\text { women; Planned Parenthood; } \\
\text { Abortion; Contraceptives }\end{array}$ & 8 \\
\hline $\begin{array}{c}\text { State and } \\
\text { international } \\
\text { affairs }\end{array}$ & $\begin{array}{c}\text { Flint water crisis; Oil spill in } \\
\text { the Amazon's waterways }\end{array}$ & 7 \\
\hline $\begin{array}{c}\text { Other social } \\
\text { topics }\end{array}$ & $\begin{array}{c}\text { Anxiety disorder; Unfair } \\
\text { treatment of mental health } \\
\text { patients in the ER room }\end{array}$ & 5 \\
\hline $\begin{array}{c}\text { Economy } \\
\text { tuition; poverty }\end{array}$ & $\begin{array}{c}\text { Rising minimal wage; college } \\
\text { Table }\end{array}$ & 5 \\
\hline
\end{tabular}

Table 1. Topics of diary notes discussed in interviews regarding political and social issues found on Facebook. 


\begin{tabular}{|c|c|c|c|c|c|c|c|}
\hline & N & \multicolumn{3}{|c|}{ Gender } & \multicolumn{4}{|c|}{ Year in School } \\
\hline & & M & F & $\mathbf{1}$ & $\mathbf{2}$ & $\mathbf{3}$ & $\mathbf{4}$ \\
\hline Total & 50 & 21 & 29 & 11 & 12 & 13 & 14 \\
\hline Facebook & 34 & 12 & 22 & 7 & 8 & 10 & 9 \\
\hline $\begin{array}{c}\text { Mainstream } \\
\text { News outlets }\end{array}$ & 5 & 5 & 0 & 0 & 3 & 1 & 1 \\
\hline Other sources & 4 & 2 & 2 & 1 & 1 & 1 & 1 \\
\hline $\begin{array}{c}\text { Do not read } \\
\text { news }\end{array}$ & 12 & 5 & 7 & 3 & 2 & 3 & 4 \\
\hline
\end{tabular}

Table 2. Types of news readers and demographic information. Note that participants could be coded into using more than one news source.

subcategory of Facebook news readers. The two coders compared their codes and gave each other their rationales if there were disagreements. Initially, there were disagreements on major profiles for six participants and on Facebook news reader type for five participants. After the discussion, the two coders resolved the disagreements and agreed $100 \%$. We did not calculate a Cohen's Kappa for inter-rater reliability because some participants were assigned more than one major profile or Facebook news reader type.

\section{RESULTS}

\section{Overview of News Sources}

The majority $(\mathrm{N}=34)$ of our sample of college students used Facebook as their primary news source. We summarized the breakdown of the main news reader profiles in Table 2, with basic demographic information. Because of the small sample size, statistical tests to compare the characteristics of these subgroups would not yield meaningful results. We nevertheless observed that Facebook news readers tend to be female. In comparison, five students, all male, used mainstream news outlets as their primary news source. They praised the formality and professionalism of reputable news sources like CNN, NBC, and The New York Times, and believe Facebook to be "different people arguing" using one-sided arguments without facts to back them up. Furthermore, two of these five mainstream news readers were concerned about the biased coverage of news as a result of the newsfeed algorithm.

Though 34 participants used Facebook for their news needs, the primary sources for news of politics or social issues within Facebook were diverse. A little more than half (19) relied on friends' posts, which included original postings of personal opinions on news along with likes, comments, or shares of news from other publishers. Twelve participants mainly glanced at the trending topics, which were aggregates of different sources of, and discussions about, the same news topic. Others deliberately chose to subscribe to specific sets of sources in order to personalize what they want to read - seven students primarily read from popular media producers (e.g., Buzzfeed, AJ+, NowThis), and five from mainstream news outlets. Note that some participants used more than one primary source on Facebook.

With these different news sources, we first uncover the gratifications students experience in the next section. This will give us some insights into why college students consume news on Facebook, an action that grounds their practices in discussing and disseminating news. Participation in news is heavily influenced by social norms around disclosure and impression management, which we will detail in the section that follows.

\section{Gratifications of Engaging in Facebook News}

Convenience of access

Getting news from Facebook is often a byproduct of college students' daily social and communication routine, and therefore takes little extra time or effort. P22 talked about why she liked to read news from Facebook:

"I'm already going to message someone. I'm already there. There are a lot of things to do in one place, and that makes it easier." (P22)

More than half of the Facebook news readers (20) commented that they would not have gone out of their way to seek news or check updates from news sites because it is "too much work" outside of their daily routine, especially when their goal is to get a general understanding of current issues instead of deep engagement. P46 described: "I don't want to know too much about it but I don't want to know too little about it." Requiring minimal effort, Facebook becomes an outlet for news: some glance at the trending topics to get an overview of the public interests, some let various news media push breaking news to their newsfeed, and others inevitably encounter friends' recommendations due to the nature of social networking.

\section{New perspectives and social sense making}

Besides the convenience of access, 26 out of 34 Facebook news readers believed that they were able to get fuller coverage of news compared to using any single news source and/or to develop a better understanding of current issues because of the comments and personal reflections from peers. We call this benefit gaining new perspectives and enabling social sense making.

Though a small number, four students intentionally subscribed to diverse news sources in order to have different news articles on the same topic pushed to their newsfeed. Five students explicitly commented that they read the trending topics, not just for convenience, but to get "a review of the spectrum of the different opinions" (P1). Granted that anyone who is interested can search on multiple news sources to eliminate the influence of media bias on them, Facebook helps simplify such a "manual checking" process. Exposure to multiple perspectives either through intentional configuration of sources or 
unintentional encounters can potentially encourage college students to find "the middle ground" (P22, P9) while still allowing them to have instant access with relatively low effort.

"I like and follow the pages for the New York Times, the Washington Post, the Atlantic, Fox news, CNN, and because I follow all five of those at least, probably more than that, I can see all of their posts whenever they go on and I'll just scroll to those and see through that. I enjoy seeing a lot of people are quick to dismiss Fox as being not credible towards everything and same with CBS and $M S N B C$. I think they are both incredibly credible if you read them together. If you read the liberal bias of $N B C$ and the conservative bias of Fox, then you get at least some sense of a picture of this is what people are thinking." (P48)

P9, a self-proclaimed feminist, was raised in a Republican household, growing up watching Fox news. She is now an enthusiastic advocate for women's reproductive rights. She attributed her change in values and development of a new identity to the different opinions she read from Facebook and social media. These different views encouraged her to question her old values and identify with a new perspective.

"Before Facebook, before social media, I was just kind of in my own world. Whatever I saw on the news, or whatever my parents told me was right. And now I'm realizing 'no, just because it's on Fox news or because my dad says it doesn't mean it's right.' I think figuring out who I am and what I believe has been part of being on Facebook and on social media, because I see different opinions and I'm like 'Oh wait, I think I agree with that more than what I used to agree with because I didn't know any better. Because I only had a limited source of news. '” (P9)

For those who have yet to adopt a media-diversifying strategy on Facebook, they frequently talked about how they chanced upon friends' posts. These posts give them a new perspective on a topic or a new set of interests they would not otherwise seek out proactively. For example, P4 is usually interested in reading about science and public health on Facebook, and her friend's posts expanded her interest:

"She's very much like 'equality' and 'diversity' and all that kind of stuff...And I think it's good that she posts stuff like that because it's very different from what I normally look at, or what I normally post, in that way it gives me information, teaches me, on the other side of the spectrum." (P4)

Besides aggregating multiple views and providing new perspectives, comments and personal reflections helped some participants make sense of news. P33 stated that she read the comments to "get it" since she often does not understand the context or implications just by reading the news. Personal inputs like comments provided "dumbeddown" interpretations of news. For others, these pointers provide additional resources to help the readers reflect and come up with their own understanding of the issues. For instance, P45 found out the real concern behind the lifelike Scarlett Johansson robot through reading friends' comments:

"Actually without the part of the commentary, I would have thought it was cool because I do like her as an actress and I probably wouldn't have thought about the fact that it was really objectifying women. Actually, I didn't think about how Siri is a woman and Cortana is a woman, I didn't really think about how they are all women to serve through robotic means until someone pointed it out in the comments." (P45)

Besides the influence of individuals, students reported benefiting from the crowd effect: they were able to access grass-roots eyewitness information that might not be covered in major news outlets and take a public pulse on sensitive topics by reading the top comments. In sum, we observed that a number of participants acquired new perspectives and were able to better make sense of news using the input from friends and the crowd.

\section{Enhanced personal relevance}

Consuming news on Facebook made it more personally relevant for individuals. For 22 participants, reading posts of political and social issues on Facebook resonated with them on a personal level. Some participants asserted that the way politics and social issues is portrayed on Facebook is "heartfelt" and something "you won't see on a website that has statistics." (P29) The personal stories, video footage, and pictures make politics and social issues more approachable. For instance, P28 described a friend's personal reflection on mental health to be "easier to understand instead of having an official talk about it."

Enhanced personal relevance helps students connect the stories of others to their own life. Such a personal connection can inspire compassion and empathy. P35 described how she felt after reading a friend's personal account of how patients with mental illness were treated unfairly in an emergency room: "I personally don't suffer from any kind of mental or psychological issues. But I do know people who have and I know that it can be tough. I guess it's relevant to my life in this way... the value is just developing empathy and think about it a little bit more." (P35)

P2, a Syrian born and raised in the U.S., commented on how reading stories about Syrian refugees from the public page of Humans of New York helped her connect with her roots and inspired her to raise awareness of the refugee situation:

"It is different to go on Facebook and see more personal issues, very personal, because it is almost like, that's the city where my family is from, and that's the city I visited when I was younger. And to see those things and to hear about them what's going on socially and politically, those 
really carried an impact with me, and I'd like to shed light on those issues and share them so that people can learn something from that." (P2)

Finding personal relevance in news helps college students recognize their interests and develop their own stances, as we have seen here. In the next section, we explore the social processes that influence students' disclosure and selfpresentation behavior around news on Facebook.

\section{Self-presentation around News on Facebook}

Reflecting on their early Facebook behavior and current practice, participants reported that they are now more selective about what information they disseminate and how they express themselves through shares, likes, or comments. These changes are due to concerns about privacy and being socially acceptable, similar to the results found in Schoenebeck et al.'s recent work [36]. While the accepted social norms on Facebook are changing overall, participants expressed an even more pressing need to figure out the desirable behavior around topics of politics and social issues, as posts of these topics are growing in quantity and visibility on Facebook.

In this section, we first present the social benefits students experience when engaging with Facebook news, because these social benefits can affect how they manage their own social presence around news.

\section{Social benefits influence self-presentation}

Fifteen students reported that engaging with politics and social issues on Facebook promoted social engagement, including staying in the loop, staying aware of friends' political stances or viewpoints on controversial issues, and strengthening social relationships between like-minded friends.

Being "less ignorant" (P15) and "able to talk to friends" (P20, P44) in an offline context are important to college students. News that serves a social function in our civic life is not new. However, what is interesting is that Facebook puts the news topics of friends' interests on public display, providing the viewers with a "quick study" of the topics that are likely to be talked about in an offline context. In addition, some use Facebook to learn about friends' political stances in order to satisfy their personal curiosity or to take an informal poll.

"It's fun when somebody posts something controversial, and then you can see you have some friends who are on this side of argument or some friends who are on the other side. And I found that I've had friends who I thought were very liberal, and they actually have some very conservative viewpoints one way or another." (P16)

For others, communicating about news through lightweight activities (e.g., sharing or liking an article) is a way to strengthen social relationships among people who already share similar views. For example, P4 talked about how she appreciated a news article about HPV vaccination from friends:

"I do have nerdy friends on Facebook, so we just send back and forth articles. The HPV article was linked by a friend who re-posted it. They tagged me in it saying "hey I think you'd like this.' I was like 'OK, cool!'” (P4)

However, not all inputs from friends are accepted. After discovering that one of her friends had a different view than she expected, P16 jokingly said: "Wow! I did not know that, un-friend!" In other words, students benefit from friends disclosing their interests or opinions in order to gain social awareness of popular topics as well as other individuals' stances. They then either warmly accept (like P4) or judge others' input (like P16). Perhaps, by recognizing how they react to other people's posts, students realize the fact that their own disclosure can also result in acceptance or rejection by others, which in turn influences their own disclosure practice around news.

Concerns and goals for impression management and disclosure

We found that participants pay close attention to what and how they broadcast news in order to communicate a version of themselves that is considered appropriate. Since appropriateness is contingent upon audience perceptions, imagining the audience's reactions and figuring out who the audiences are, impact students' decision-making around news.

Some participants posited that the audience would derive information about their personal character based on the content they are interested in. When talking about her liking of Michael Dyson's unconventional view on President Obama, P2 commented: "I'm very particular about what I like and share, it's going to mean something... When people see that I liked it, they'll be like 'Oh Nora [pseudonym] liked it, I'm interested in seeing what she likes."'

Some participants felt that the audience would speculate on how involved the posters were in a particular topic: "If I just like it, people might see that I liked it. But if I shared it, people feel like I feel more strongly about it." (P22)

Some participants expressed their desire to appeal to their friends in order to fulfill their goal of social approval [44]. P35 commented: "I guess there is more of a peer pressure. Like when you're trying to behave the same way as your friends. So people would post things on Facebook that are similar to things their friends would post." P33, as we mentioned in the previous section, often relies on comments to understand the news. She is concerned that her participation in news might reveal her inadequacy in knowledge, and thus she would fail at being approved of by her peers: "I always want to comment on what they are saying or anything, but I don't because I'm just afraid of other people judging me for my opinion... what if I said something wrong?" (P33) 
In addition to carefully managing how they look to others at the moment, though a small number, three students are also concerned about how they might be perceived in the future. Data archives about one's political interests, stances, and development can subject a user to future scrutiny. For instance, P12 confessed that he craved multiple perspectives on politics but never gave his opinion on Facebook because he had considered a career in politics. He avoided keeping a public record "so it doesn't come back."

While the aforementioned students feel that they open themselves up for investigation when engaging with debatable topics, others are concerned about the impact of their actions on other people or on the community. Presenting different views can start a heated public argument or even jeopardize friend or family relationships. Not disclosing views is intended to create harmony.

"We have opposing political views and so if I shared it, it would turn into a debate and I'd rather just keep Facebook for entertainment." (P32)

Besides creating a desirable self-image and keeping conflicts out of friend circles, others are simply trying to avoid destructive interactions. Five participants commented that the social interactions around news they have experienced or viewed are often fruitless. In order to avoid uncivil comments, some choose to withhold sharing anything with an opinion. For instance, P9 loves reading posts about Planned Parenthood, but she does not share posts publicly about the topic any more, because:

"Every time I share something with Planned Parenthood, I have this one guy that says 'they kill babies!' 'They sell baby parts!"' (P9)

Strategies for impression management and disclosure goals In order to maintain a desirable impression, it is important for a user to identify for whom they are performing. Diverse audience groups (e.g., colleagues, family, middle school classmates, romantic partners, weekend hobby buddies) are merged into one singular friend list on Facebook, also known as context collapse. As a result, it is increasingly difficult for users to accurately tailor what they disclose and how, to the right audience [45]. A number of our participants have adopted the lowest common denominator strategy, a metaphor used by Hogan [19] to describe how a user refrains from posting content that any of their audience groups might potentially find problematic, so as to maintain an acceptable self to all audience groups.

"How would it look to my grandma who's reading this? That's why I filter my thoughts and I won't post anything too political or too out there because I know my parents see it, and my grandparents and other family members - people I want to respect me." (P9)

"I have a good number of friends who are on the right and others who are on the left... With me being plugged into the drama department, you can imagine there are a lot of
Sanders supporters here and I am not personally a Sanders supporter. So I look at that and think if I have an article I think is interesting, but it speaks against Sanders or discredits him in some way, nothing good is going to come out of sharing this." (P48)

P48's comment demonstrates the use of the lowest common denominator strategy, but it also reflects a bigger issue: audience groups can be created beyond the boundary of traditionally defined social groups. Content of posts (e.g., favoring a specific politician) can also delimit distinct audience groups. The dynamic nature of online audience groups (as opposed to comparatively stable audience groups such as family or co-workers) requires users to constantly examine the different audience groups given the topic.

To mitigate this challenge, some students made sharing decisions based on whether they felt the content would potentially create audience groups whose competing values might lead to negative interactions. P40 stated that he only shares articles about art and never politics:

"Because I feel like with art everyone can appreciate art in some type of way. There won't be as much bickering. But with politics, there could be arguments." (P40)

In addition to refraining from sharing or commenting, we also observed participation in a controlled manner, including addressing specific audiences and using a neutral tone. Similar to the notion of targeted disclosure from Vitak and Kim's work [44], some participants created a customized space for the intended audience as a way to manage context collapse around political topics.

"I don't share a lot of things publically. When I share something it's usually... there is an option called 'share in a private message,' and I'll share it to somebody I want to tell it to." (P16)

"You can create a secret group with your close friends, it's like a newsfeed just for your friends. I post links on there, they can comment whatever they want. They are usually the ones I'm trying to send them [the links] to anyways, so instead of sharing it to everyone, I just share to them." (P20)

Others adopted a neutral tone to "test the waters" when sharing an article. Instead of throwing out their opinion, they framed the shared article as a means for eliciting different ideas instead of representing their own stance:

"I'll just share it and I don't comment anything... I do have friends who are very conservative and some that are extreme liberals, politically speaking, so if I were to post something friendships get heated. So it's better to just say 'oh look at this, what do you think?' At that point I say 'what do you think?' because they can read it and comment on it." (P12)

And for those who are concerned about managing their image for the future, besides putting themselves "on mute" 
(P12), P22 sought to strike a balance between voicing her opinions in the short term and avoiding leaving a public record for the long term:

"If I like something, someone else would see it too (on their newsfeed), it's for the awareness sake...but if I share it, it's on my actual timeline. And sometimes I end up deleting them after a while. Because I don't want too many people know exactly what I shared. It's been a couple of weeks, so it's not on anybody's newsfeed any more, so there is no point of me having it on my record." (P22)

So far, we observed that it is common for students to refrain from voicing undesirable opinions to audience groups they know would be upset or to self-censor topics that can potentially create audience groups in conflict. We also found a number of controlled participation tactics such as targeting the audience using (semi-)private channels, adopting a neutral tone to elicit opinions, and using a temporal strategy to participate in the short term without leaving data records. Furthermore, a small group of people proposed a shift of norms by changing the climate of debate on Facebook.

One participant stated that it was important to change the way people talk about issues like politics, after he read a long post written by his friend:

"This one is from my friend. He is giving a general overview of his political views and the rest of it talks about the nature of debating an argument and his opinion on it, and how he wants people to debate and argue him to foster dialogue between different points of views. He also goes on about how it's sad that when people argue or debate and they don't agree, then it becomes personal, and that is a reason for them to stop being friends." (P50)

P50 confessed that he was the type of person his friend was talking about - alienating friends who do not share his views. After reading the post, he reflected on his own behavior and sided with his friends. P26 and P30 shared a similar sentiment that even though they have observed unpleasant exchanges on Facebook regarding topics people have different views about, they still hope to see more rather than less of those conflicts.

"It helps people who are ignorant to know about issues and then they get educated. Sometimes, keeping things public helps." (P30)

\section{DISCUSSION}

In this paper, we interviewed 50 students who regularly use Facebook in their everyday college life, to understand their practices, gratifications, and concerns around political and social issues on Facebook. We observed two main themes: one centers around news consumption on Facebook, the other focuses on the self-presentation aspect of news participation on Facebook. First, because of Facebook, students are now getting news exposure more easily, often times with different view points, peer contributions, or a personal connection. We also observed that consuming what others disclosed helps students gain social benefits around news, yet this also motivates them to be reflective and cautious about their own participation around news. In particular, participants manage their self-presentation around news sharing, commenting, or liking by imagining who the audience members are, what their reactions might be, and what they consider desirable. This often causes the students to refrain from participation or resort to controlled participation that does not subject them to public scrutiny. In the following, we discuss design implications and future directions to address these two themes.

\section{Leveraging the Convenience Value and Multiple Perspectives}

We found 20 students relying on Facebook news for its convenience because Facebook fits into their daily social and communication routine. Easy access to news encourages students who otherwise might not read news to be aware of current political and social issues with minimal cost. However, since these students are likely to view the trending topics or simply glance at items in their newsfeed without making further efforts to follow up, they are susceptible to the algorithmic selection bias [10].

Specifically, while a few students commented that Facebook users like to connect with people who share similar views, only one Facebook news reader and two nonFacebook news readers critiqued the newsfeed algorithm effect. That is, the algorithm presents the users with what they want to see based on their past activities and preferences. Also, it is somewhat surprising that no participant raised any questions or comments on why a news story became a trending topic. In fact, some perceived the trending topics to be filtered by the general public, representing the true interest of the crowd. While not completely wrong, recent media attention [15] on the potential systematic political biases (or the lack thereof [39]) in trending topics has demonstrated the lack of transparency on these critical design choices to users. In response, Facebook released a news report on May 12, 2016, stating that the trending topic is a product of algorithm, human judgment, and personalization [30].

We propose to leverage the convenience value and the potential of gaining multiple perspectives through power users. Though a small number, we found four students proactively compose their newsfeed by subscribing to multiple news sources in order to access different view points. We do not intend to generalize this observation to most college students. In fact, most of our participants are convenience seeking and lacking in their awareness of or interest in the systematic biases in the media. Nevertheless, we think users like these four individuals can offer a valuable opportunity to their respective networks: Katz and Lazarsfeld's [22] model of personal influence states that information often flows from traditional forms of mass media (e.g., an article on $\mathrm{CNN}$ ) to influential readers and 
then on to a less active audience who seek guidance or social confirmation from influential readers. We therefore recommend that social media platforms support power users to share with their friends a "playlist" that includes multiple angles from multiple news sources instead of sharing a single article that could disclose one's political stances. In this way, users who have a media diversifying strategy can provide friends (especially those who spend minimal effort in obtaining news items) with a higher chance of exposure to multiple perspectives while preserving their own privacy.

\section{Addressing the Imbalance of News Consumption and News Participation}

A substantial number of students reveal that they use Facebook for news because Facebook fits into their daily social and communication routine. The convenience of " $a$ lot of things to do in one place" (P22) lowers the cost of seeking news. However, having multiple social functions, norms, and audiences in one place can increase the difficulty for a student to present a desirable image across different social contexts. This in turn could raise the cost of news participation as self-presentation affects what one discloses and shares when it comes to news. We observed an imbalance between students taking advantage of the participation of others while contributing little or none themselves, i.e. the long tail that occurs with other online phenomena such as Wikipedia use. For instance, students reported reading the news shared or liked by friends as a way to be in the loop or to know friends' political interests and stances. Meanwhile, the majority of the participants either participated in a carefully controlled manner (e.g., in a private message channel) or refrained from participating at all in order to not upset any audience group or to avoid unconstructive interaction. This is consistent with a previous study on social control to maintain a level of constraint [44]. Our findings could also complement previous studies, which found that users adjust the visibility of their profile to manage an unwanted audience [42] while not reducing the amount of information they disclose on their profile [42, 47]. We showed that students' concerns negatively impact their disclosure of potentially debatable information around politics and social issues beyond profile management.

Currently, when a user likes, shares, or comments on a post, the action is by default broadcast to her entire network through the newsfeed, unless the user specifies the privacy settings of each post. Given the concerns around visibility, we urge future studies to explore in detail local vs. global sharing of news.

As we have seen, in the context of online interactions with political and social issues, the boundary between different audience groups is less easily defined. Take P9 for example, she was aware that the conservative views of her father and grandmother would clash with her progressive views. But simply customizing her posts to family and non- family-members would not solve her problem, since a Facebook friend who was not a family member left uncivil comments on topics related to Planned Parenthood. Also, in the case of P48, he has liberal and conservative friends on Facebook. Within his liberal friends, some support Bernie Sanders while he himself does not; and these Sanders supporters can often be found in the drama department, where P48 also has close connections because of his photography interests. Context collapse occurs at a much more granular level than traditionally defined social groups and can be amorphous based on the particular content. When the complexity of context collapse is driven by the content (e.g., support for a politician) as well as by traditional social groups (e.g., the drama department), current available solutions on Facebook such as creating static customized groups are not scalable. It is therefore not surprising that they resort to a lowest common denominator strategy. We urge future studies to take into account the dynamic nature of collapsed context on Facebook.

Social media data are used both for synchronous performances and asynchronous exhibitions [48]. Political interests, stances, worldviews, and even the taste of music and books can change over time. We think this is important not only for those who have overtly expressed concerns for the future, like P12 who considers a career in politics, but also for individuals at large who are in a life stage where changes are expected. In our study, multiple cases point to this notion: P9, who switched from a conservative background to progressive thinking as a result of exposure to news on social media; P33, who struggled to catch up with the current political happenings; and P50, who reflected on his previous tendency of alienating friends with different views and who is now advocating for a change of climate in discussing politics. In the current design of the platform, Facebook has limited capacity to accommodate these changes because the timeline by default archives data history and the newsfeed by default broadcasts every action. Therefore, users either manage their data archive retrospectively by deleting or privatizing posts [36] or as our participants reported, they opt out of participating or participate in private channels because of potential concerns. In order to better accommodate change and support young users' evolving identities, we believe it is a fruitful line for future study to explore the varying levels of visibility and retrievability of user generated content over time.

\section{Limitations and Generalizability}

We have several limitations in this study. First, our participants were students who use Facebook for at least three times a day. Therefore, our findings are only generalizable for college students who use Facebook regularly on a daily basis. However, it has been found that most college students do use Facebook regularly [46]. We also do not suggest that the majority of college students use Facebook as a primary news source, since college students who do not use Facebook or use Facebook infrequently 
may rely on other news sources. Second, we only collected and discussed political and social issues encountered on the desktop version of Facebook. It is possible that students' practices and concerns around mobile news are different. For example, while trending topics are easily visible on the desktop version, they are hidden under the search box for the mobile Facebook interface. Thirdly, the diaries and interviews questions prompted participants to record and discuss cases they found interesting, valuable, or of learning value, pointing to a value oriented study design. Instances where students are susceptible to selection bias and echochamber effects, as frequently shown in previous studies $[1$, $4,16]$ are likely to have been missed by our data collection.

\section{CONCLUSION}

Guided by an open question of how college students use Facebook for news of political and social issues, we conducted a qualitative investigation with 50 college students. The majority of these regular Facebook users in our sample use the platform as their primary news source by following friends, trending topics, mainstream media outlets, or popular media producers. They experience multiple benefits associated with Facebook news, such as the ability to access different viewpoints, engage in social sense making, or form a personal connection with the news. However, students are also concerned about their selfpresentation around news and often choose to refrain from participation to avoid conflict, resulting in an imbalance between news consumption and news participation on Facebook. These results shed light on the debate about the role that social media plays on youth political participation and they also serve to extend the discussion of context collapse and self-presentation on social media.

\section{ACKNOWLEDGMENTS}

We thank Josceline Maldonado, Jackeline Maldonado, and Nadira Yang, for their help in transcribing and coding the interviews; Felix Epp, Oliver Hoffmann, and Andreas Poller for their help in customizing the data collection tool ROSE; and the anonymous reviewers for their feedback on the paper. This work is supported by the National Science Foundation Grant (\#1218705) and Air Force Office of Scientific Research Grant (\#FA9550-15-C-0032).

\section{REFERENCES}

1. Lada Adamic and Natalie Glance. 2005. The political blogosphere and the 2004 US election: divided they blog. In Proceedings of the 3rd International Workshop on Link Discovery, 36-43.

2. Elena Agapie and Sean Munson. 2015. Social cues and Interest in reading political news stories. ICWSM'15.

3. Jeffrey J. Arnett. 2000. Emerging adulthood: A theory of development from the late teens through the twenties. American psychologist 55, 5: 469-480.

4. Eytan Bakshy, Solomon Messing, and Lada Adamic. 2015. Exposure to ideologically diverse news and opinion on Facebook. Science 348, 6239: 1130-1132.
5. Michael Barthel, Elisa Shearer, Jeffrey Gottfried, and Amy Mitchell. News use on Facebook and Twitter is on the rise. Pew Research Center Report. (14 July, 2015). Retrieved May 26, 2016 from http://www.journalism.org/2015/07/14/news-use-onfacebook-and-twitter-is-on-the-rise/

6. Michael Barthel, Galen Stocking, Jesse Holcomb, and Amy Mitchell. Seven-in-Ten Reddit users get news on the site. Pew Research Center Report. (25 February, 2016). Retrieved May 26, 2016 from

http://www.journalism.org/2016/02/25/seven-in-tenreddit-users-get-news-on-the-site/

7. Jody C. Baumgartner and Jonathan S. Morris. 2010. MyFaceTube politics: Social networking web sites and political engagement of young adults. Social Science Computer Review 28,1: 24-44.

8. Jody C. Baumgartner, Jonathan S. Morris, Natasha L. Walth. 2012. The Fey effect: Young adults, political humor, and perceptions of Sarah Palin in the 2008 presidential election campaign. Public Opinion Quarterly 76,1: 95-104.

9. Benjamin T. Bowyer, Joseph E. Kahne, Ellen Middaugh. 2015. Youth comprehension of political messages in YouTube videos. New Media \& Society, doi: $10.1177 / 1461444815611593$

10. Engin Bozdag. 2013. Bias in algorithmic filtering and personalization. Ethics and Information Technology 15, 3: 209-227.

11. Jennifer Brundidge. 2010. Encountering "difference" in the contemporary public sphere: The contribution of the Internet to the heterogeneity of political discussion networks. Journal of Communication, 60, 4: 680-700.

12. Jihyang Choi and Jae Kook Lee. 2015. Investigating the effects of news sharing and political interest on social media network heterogeneity. Computers in Human Behavior 44: 258-266.

13. Juliet Corbin and Anselm Strauss. 2008. Basics of Qualitative Research: Grounded Theory Procedures and Techniques 3rd edition. Thousand Oaks, CA: Sage.

14. Nicole Ellison, Rebecca Heino, Jennifer Gibbs. 2006. Managing impressions online: Self-presentation processes in the online dating environment. Journal of Computer-Mediated Communication 11, 2: 415-441.

15. Facebook's Zuckerberg to meet conservatives on political bias flap. Reuters. (15 May, 2016). Retrieved May 26, 2016 from

https://www.yahoo.com/news/facebooks-zuckerbergmeet-conservatives-political-bias-flap-203435246-finance.html

16. Seth Flaxman, Sharad Goel, and Justin Rao. 2016. Filter bubbles, echo chambers, and online news consumption. Public Opinion Quarterly 80,1: 298-320. 
17. Homero Gil de Zúñiga, Nakwon Jung, Sebastián Valenzuela. 2012. Social media use for news and individuals' social capital, civic engagement and political participation. Journal of Computer-Mediated Communication 17, 3: 319-336.

18. Catherine Grevet, Loren G. Terveen, Eric Gilbert. Managing political differences in social media. In Proceedings of the ACM conference on Computer Supported Cooperative Work \& Social Computing (CSCW'14), 1400-1408.

19. Bernie Hogan. 2010. The presentation of self in the age of social media: Distinguishing performances and exhibitions online. Bulletin of Science, Technology \& Society, doi: 10.1177/0270467610385893

20. Gary Hsieh, Jilin Chen, Jalal U. Mahmud, and Jeffrey Nichols. 2014. You read what you value: understanding personal values and reading interests. In Proceedings of the SIGCHI Conference on Human Factors in Computing Systems (CHI '14), 983-986.

21. Joseph Kahne, Erica Hodgin, Elyse Eidman-Aadahl. 2016. Redesigning civic education for the digital age: Participatory politics and the pursuit of democratic engagement. Theory \& Research in Social Education 44, 1: 1-35.

22. Elihu Katz, and Paul F. Lazarsfeld. 1955. Personal Influence, The part played by people in the flow of mass communications. Transaction Publishers.

23. Nicole C. Krämer and Stephan Winter. 2008. Impression management 2.0: The relationship of selfesteem, extraversion, self-efficacy, and selfpresentation within social networking sites. Journal of Media Psychology 20, 3: 106-116.

24. Matthew J. Kushin and Masahiro Yamamoto. 2010. Did social media really matter? College students' use of online media and political decision making in the 2008 election. Mass Communication and Society 13, 5: 608630 .

25. Q. Vera Liao and Wai-Tat Fu. 2014. Expert voices in echo chambers: Effects of source expertise indicators on exposure to diverse opinions. In Proceedings of the SIGCHI Conference on Human Factors in Computing Systems (CHI '14), 2745-2754.

26. Karen Locke, Martha S. Feldman, Karen GoldenBiddle. 2015. Discovery, validation and live Coding. In Handbook of Qualitative Organizational Research, Kimberly D. Elsbach and Roderick M. Kramer (eds). Routledge, Taylor and Francis Group.

27. Ben Marder, Emma Slade, David Houghton, and Chris Archer-Brown. 2016. "I like them, but won't 'like'them": An examination of impression management associated with visible political party affiliation on Facebook. Computers in Human Behavior 61: 280-287.
28. Sean A. Munson and Paul Resnick. 2010. Presenting diverse political opinions: How and how Much. In Proceedings of the SIGCHI Conference on Human Factors in Computing Systems (CHI '10), 1457-1466.

29. Anne Oeldorf-Hirsch and S. Shyam Sundar. 2015. Posting, commenting, and tagging: Effects of sharing news stories on Facebook. Computers in Human Behavior 44: 240-249.

30. Justin Osofsky. Information about trending topics. (12 May, 2016) Retrieved May 26, 2016 from http://newsroom.fb.com/news/2016/05/informationabout-trending-topics

31. Iryna Pentina and Monideepa Tarafdar. 2014. From "information" to "knowing": Exploring the role of social media in contemporary news consumption. Computers in Human Behavior 35: 211-223.

32. William G. Perry. 1998. Forms of Ethical and Intellectual Development in the College Years: A Scheme. San Francisco: Jossey-Bass.

33. Andreas Poller, Petra Ilyes, Andreas Kramm, and Laura Kocksch. 2014. Investigating OSN users' privacy strategies with in-situ observation. In Proceedings of the companion publication of the ACM conference on Computer Supported Cooperative Work \& Social Computing (CSCW Companion'14), 217-220.

34. Margaret Rundle, Emily Weinstein, Howard Gardner, and Carrie James. 2015. Doing civics in the digital age: Casual, purposeful, and strategic approaches to participatory politics. (30 September, 2015). Retrieved May 26, 2016 from http://ypp.dmlcentral.net/publications/238/

35. Dietram A. Scheufele, Matthew C. Nisbet, Dominique Brossard, and Erik C. Nisbet. 2004. Social structure and citizenship: Examining the impacts of social setting, network heterogeneity, and informational variables on political participation. Political Communication 21, 3: 315-338.

36. Sarita Schoenebeck, Nicole B. Ellison, Lindsay Blackwell, Joseph B. Bayer, and Emily B. Falk. 2016. Playful backstalking and serious impression management: How young adults reflect on their past identities on Facebook. In Proceedings of the ACM conference on Computer Supported Cooperative Work \& Social Computing (CSCW'16), 1475-1487.

37. Seth J. Schwartz, Byron L. Zamboanga, Koen Luyckx, Alan Meca, and Rachel A. Ritchie. 2013. Identity in emerging adulthood reviewing the field and looking forward. Emerging Adulthood 1, 2: 96-113.

38. Bryan Semaan, Heather Faucett, Scott P. Robertson, Misa Maruyama, and Sara Douglas. 2015. Designing political deliberation environments to support interactions in the public sphere. In Proceedings of the 
SIGCHI Conference on Human Factors in Computing Systems (CHI '15). 3167-3176.

39. Colin Stretch. Response to chairman John Thune's letter on tending topics. (23 May, 2016) Retrieved May 26, 2016 from http://newsroom.fb.com/news/2016/05/response-tochairman-john-thunes-letter-on-trending-topics/

40. Cass R. Sunstein. 2002. The law of group polarization. Journal of Political Philosophy10, 2: 175-195.

41. The most popular social issues of 2016. Retrieved May 26, 2016 from https://www.isidewith.com/polls/social

42. Zeynep Tufekci. 2008. Can you see me now? Audience and disclosure regulation in online social network sites. Bulletin of Science, Technology \& Society 28, 1: 20-36.

43. Jessica Vitak. 2012. The impact of context collapse and privacy on social network site disclosures. Journal of Broadcasting \& Electronic Media 56, 4: 451-470.

44. Jessica Vitak and Jinyoung Kim. 2014. You can't block people offline: examining how Facebook's affordances shape the disclosure process. In Proceedings of the ACM conference on Computer Supported Cooperative Work \& Social Computing (CSCW'14), 461-474.
45. Jessica Vitak, Stacy Blasiola, Sameer Patil, and Eden Litt. 2015. Balancing audience and privacy tensions on social network sites: Strategies of highly engaged users. International Journal of Communication 9, 20: 1485-1504.

46. Yiran Wang, Melissa Niiya, Gloria Mark, Stephanie M. Reich, and Mark Warschauer. 2015. Coming of age (digitally): An ecological view of social media use among college students. In Proceedings of the ACM conference on Computer Supported Cooperative Work \& Social Computing (CSCW'15), 571-582.

47. Alyson L. Young and Anabel Quan-Haase. 2009. Information revelation and internet privacy concerns on social network sites: a case study of facebook. In Proceedings of the Fourth International Conference on Communities and Technologies, 265-274.

48. Xuan Zhao, Niloufar Salehi, Sasha Naranjit, Sara Alwaalan, Stephen Voida, and Dan Cosley. 2013. The many faces of Facebook: Experiencing social media as performance, exhibition, and personal archive. In Proceedings of the SIGCHI Conference on Human Factors in Computing Systems (CHI '13), 1-10. 